\title{
Liao ning virus in China
}

\author{
Zhi Lu', Hong Liu', Shihong Fu', Xinjun Lu', Qiang Dong², Song Zhang², Suxiang Tong ${ }^{2}$, Minghua Li', \\ Wenjuan Li ${ }^{1}$, Qing Tang ${ }^{1}$ and Guodong Liang ${ }^{1 *}$
}

\begin{abstract}
Background: Liao ning virus is in the genus Seadornavirus within the family Reoviridae and has a genome composed of 12 segments of double-stranded RNA (dsRNA). It is transmitted by mosquitoes and only isolated in China to date and it is the only species within the genus Seadornavirus which was reported to have been propagated in mammalian cell lines. In the study, we report 41 new isolates from northern and southern Xinjiang Uygur autonomous region in China and describe the phylogenetic relationships among all 46 Chinese LNV isolates.

Findings: The phylogenetic analysis indicated that all the isolates evaluated in this study can be divided into 3 different groups that appear to be related to geographic origin based on partial nucleotide sequence of the 10th segment which is predicted to encode outer coat proteins of LNV. Bayesian coalescent analysis estimated the date of the most recent common ancestor for the current Chinese LNV isolates to be 318 (with a 95\% confidence interval of 30-719) and the estimated evolutionary rates is $1.993 \times 10^{-3}$ substitutions per site per year.
\end{abstract}

Conclusions: The results indicated that LNV may be an emerging virus at a stage that evaluated rapidly and has been widely distributed in the north part of China.

\section{Findings}

Liao ning virus (LNV) which is the member within the genus Seadornavirus family Reoviridae was composed of 12 double-stranded RNA (dsRNA). The Seadornaviruses include three species, Banna virus (BAV), Kadipiro virus (KDV) and LNV [1]. BAV was initially isolated from patients with encephalitis and appears to be pathogenic to humans [2]. Though there have been no confirmed reports of human disease due to LNV, this virus replicates in mammalian cells and causes viraemia and haemorrhage in mice [1], suggesting LNV may be pathogenic to humans or animals [1]. Recently, LNV isolates from mosquitoes have been obtained from several regions in north China [3-5]. Here, we report additional isolates from northern and southern Xinjiang province and describe the phylogenetic relationships among Chinese LNV isolates.

A total of 41 new LNV isolates were obtained from mosquitoes during 2006 to 2008 at sites in Xinjiang province (Figure 1). Mosquito samples were collected from July to September during 2006 to 2008 from several sites in

\footnotetext{
* Correspondence: gdliang@hotmail.com

'State Key Laboratory for Infectious Disease prevention and Control, Institute for Viral Disease Control and Prevention, Chinese Center for Disease Control and Prevention, Beijing, People's Republic of China

Full list of author information is available at the end of the article
}

Xinjiang province (Latitude $39^{\circ}$ to $47^{\circ} \mathrm{N}$, Longitude $75^{\circ}$ to $86^{\circ} \mathrm{E}$ ). Mosquitoes were collected in the evening hours using UV-light traps placed in livestock sheds near human houses. Mosquitoes were sorted into pools of 50 to 100 specimens according to species. Viruses were isolated and 41 new LNV isolates were identified using previously described procedures [5]. Trizol reagent (Invitrogen, Cat No. 10296-028) was used to extract total RNA. cDNA was prepared using Ready-to-Go ${ }^{\mathrm{TM}}$ You prime First-Strand Beads Kit (Amersham Biosciences Co.) according to the manufacturer's protocol. A $576 \mathrm{bp}$ gene fragment from the 10th segment was amplified from the cDNA using previously published primers $[1,5]$. This segment was predicted to encode the LNV's outer protein which is expected to vary noticeably from one strain to another [1]. PCR products were recovered with purification kits (Qiagen) and then were sequenced directly.

The MrModeltest version $2.3 \mathrm{http}: / /$ www.softpedia. com/get/Science-CAD/MrModeltest.shtml software program was used to examine 24 models of nucleotide substitution to determine the model most appropriate for Bayesian coalescent analysis of the LNV dataset. The general time reversible evolutionary model incorporating a gamma distribution $(\mathrm{GTR}+\mathrm{G})$ was found according to the Akaike information criterion. Both strict and relaxed 


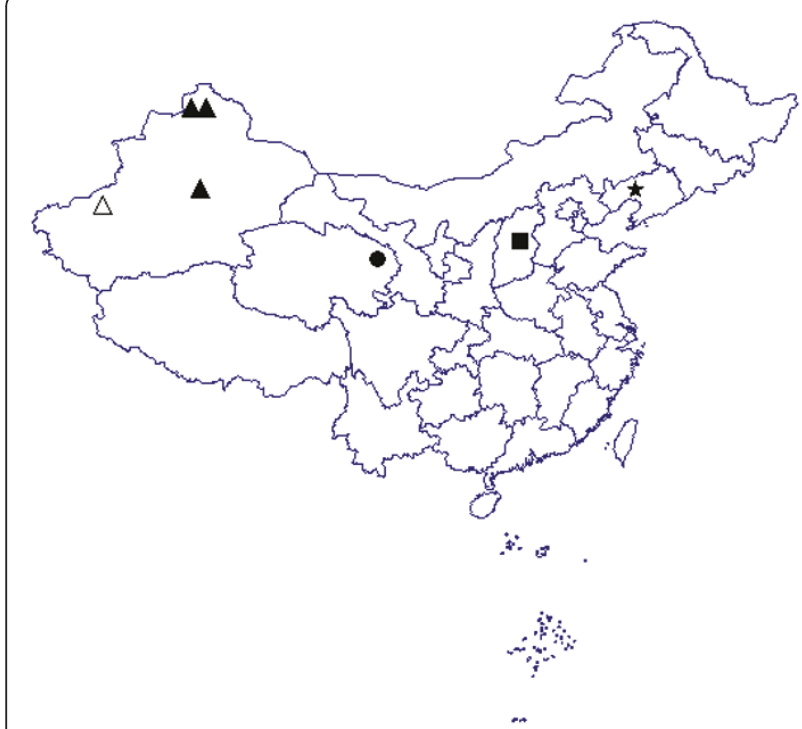

Figure 1 Location of new LNVs isolated in China. $\triangle$ Xinjiang, 2006 × Xinjiang, 2007 ॥ Xinjiang, 2008 • Qinghai, 2007 - Shanxi, $2007 \star$ Liaoning, 1997

(uncorrelated exponential and lognormal) molecular clocks [6] were employed to explore and the relaxeduncorrelated lognormal molecular clock was the best supported model, according to the estimated Bayes factor using the TRACER program. Preliminary analyses revealed that the population dynamics of LNVs supported a model of Bayesian skyline models [7]. The dataset was examined with Bayesian Markov chain Monte Carlo (MCMC) methods implemented in the BEAST package using a chain length of 100,000,000 generations with $10 \%$ removed as burn- in. All runs were checked for convergence by using the TRACER program http://tree. bio.ed.ac.uk/software/tracer/. The rate of nucleotide substitutions per site per year and the date of the time of most common ancestor (TMRCA) for these viruses were estimated. Maximum clade credibility (MCC) tree was constructed and converted to a graphics format using Figtree software version 1.2.2 http://tree.bio.ed.ac.uk/ software/figtree/.

By a Bayesian MCMC approach, the mean rate of nucleotide substitution for the10th segment of Chinese LNVs was $1.993 \times 10^{-3}$ per site per year (95\%HPD,3.664 $\times$ $10^{-4}$ to $4.667 \times 10^{-3}$ substitutions per site per year). Based on this nucleotide substitution value, the TMRCA of Chinese LNVs is estimated to be 318 (95\%HPD, 30-719) (Figure 2).

Phylogenetic analysis was conducted on 46 LNV isolates (Table 1). Of these, 41 were obtained in this study: 31 from Culex spp. in Kashi, southern Xinjiang in 2006; 7 from Culex spp. and Aedes dorsalis in Bayinguoleng, southern Xinjang in 2007; 3 from Aedes dorsalis in Aletai, northern Xinjiang in 2008(Figure 1). The other LNV isolates evaluated include: NE9712 and NE9731 isolated from Aedes dorsalis in Liaoning province in 1997 [1]; QH07130 isolated from Culex modestus in Qinghai province in 2007 [4]; SX0771 and SX0794 isolated from Culex pipiens and Aedes dorsalis in Shanxi province in 2007 [5] (Figure 1). The MCC tree shows that the LNV isolates evaluated in this study can be divided into 3 different groups that appear to be related to geographic location (Figure 2). The Xinjiang isolates are all clustered in Group A, regardless of the mosquito species from which they were isolated. Qinghai, Shanxi and one of the Liaoning isolates NE9712 are included in group B and another Liaoning isolate LNVNE9731 also from the initial isolation site of LNV was evolved independently (Figure 2). The divergence time of each lineage of the $46 \mathrm{LNV}$ isolates were also estimated by Bayesian analysis. Results showed that group A (NE9731) was the oldest lineage based on the analysis of current LNVs. As well as the diverged time of Group B and Group C was 37.7 and 18.47 , respectively. Data showed that the nucleotide and amino acid homology between the 41 LNV isolates are between $77.1-100 \%$ and $68.3-100 \%$, respectively, with NE 9731 from Liaoning province the most divergent one.

Arbovirus undergoes substantially slower rates of evolution [8]. For example, the evolution rates of Dengue virus and bluetongue virus are about $10^{-4}[9,10]$. Our results showed that the evolution rate of LNV was 1.993 $\times 10^{-3}$ which is faster than other arbovirus. In addition, the TMRAC of LNV was estimated to be 381 years, indicating LNV is an emerging virus and at a stage that evaluated rapidly to accommodate the host and the environment now. Also, the nucleotide and amino acid homology rate showed high identity within each group and much divergent between the groups. The geographical characteristic implies that LNV could raise natural circle in the locality though the diverged time of each group was quite recent.

In recent years, arbovirus surveillances have been done in many provinces. Japanese encephalitis virus, Tahyna virus, Getah virus and other arboviruses were isolated nationwide [11-13]. But all of the LNV isolates have been obtained only in region extending from Latitude $36^{\circ} \mathrm{N}$ to $47^{\circ} \mathrm{N}$ in the northwest to northeast part of the country. So for what reason, the virus has only been isolated from such a narrow geographic is too be studied.

LNV seemed to be at a stage of evolving rapidly than most of the arbovirus. Also it is much divergent between each subtype. Can such virus genetic differences have pathogenicity differences? LNV is pathogenic to mice, and seasonal encephalitis in the absence of Japanese 


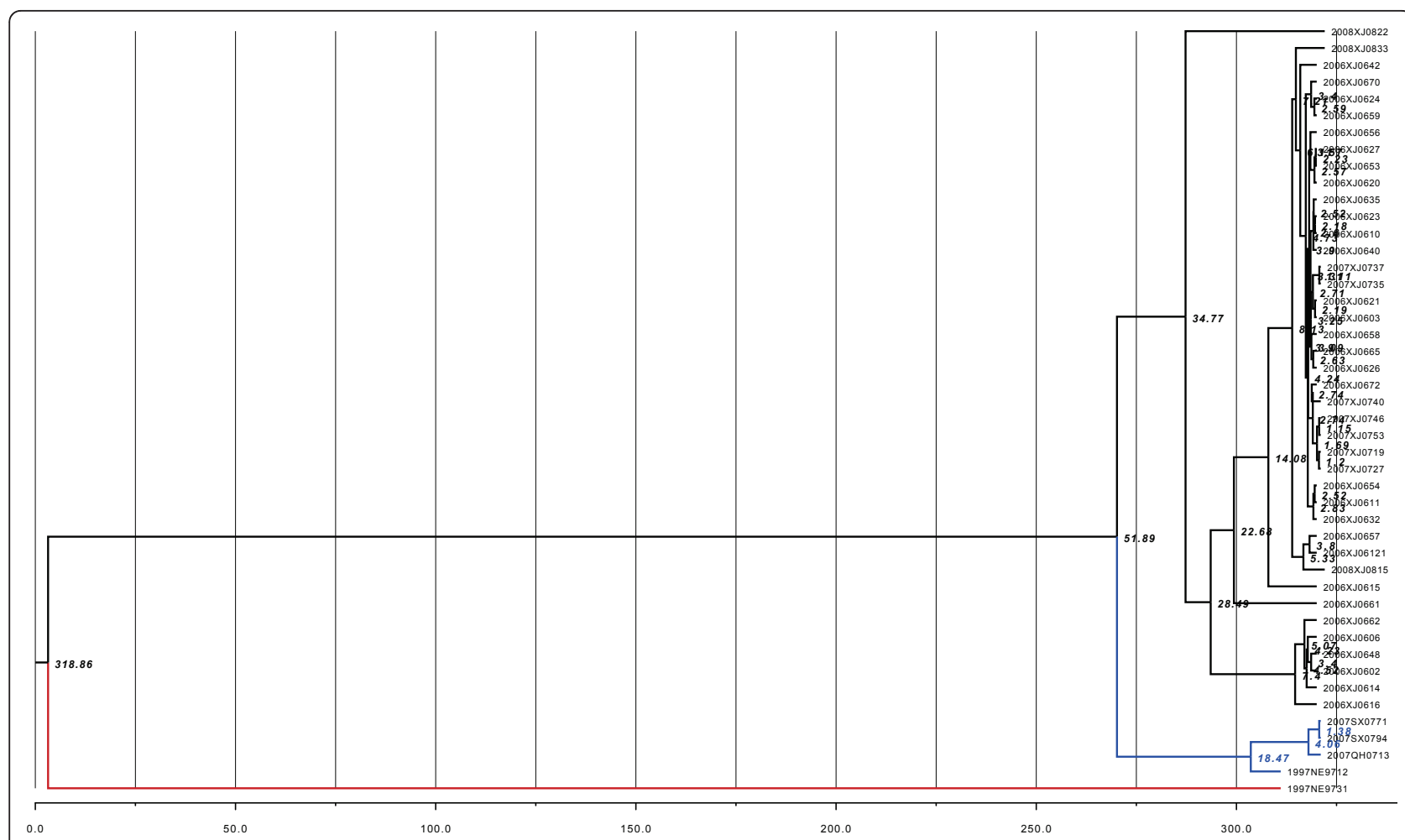

Figure 2 Phylogenetic analysis of the LNVs isolated from the China. Nucleotide of partial coding sequence of the10th segment of LNVs base maximum clade credibility (MCC) tree showing that 46 LNVs sequences from China fall into 3 groups which was colored according to different groups. The estimated TMRCA of these clades are indicated. Horizontal bar represents the scale of the estimated divergence year.

Table 1 Information of LNV isolates in China

\begin{tabular}{|c|c|c|c|c|}
\hline Province & Strain & Origin & $\begin{array}{l}\text { Time of } \\
\text { Collection }\end{array}$ & Vector \\
\hline $\begin{array}{l}\text { Kashi, southern } \\
\text { Xinjiang }\end{array}$ & $\begin{array}{l}\text { XJ0602, XJ0603, XJ0606, XJ0610, XJ0611, XJ0614, XJ0615, XJ0616, XJ0620, XJ0621, } \\
\text { XJ0623, XJ0624, XJ0626, XJ0627, XJ0632, XJ0635, XJ0640, XJ0642, XJ0648, XJ0653, } \\
\text { XJ0654, XJ0656, XJ0657, XJ0658, XJ0659, XJ0661, XJ0662, XJ0665, XJ0670, XJ0672, } \\
\text { XJ06121 }\end{array}$ & $\begin{array}{l}\text { sheep } \\
\text { house }\end{array}$ & 2006.Jul-Aug & Culex spp. \\
\hline \multirow{2}{*}{$\begin{array}{c}\text { Bayinguoleng, } \\
\text { southern Xinjiang }\end{array}$} & XJ0719, XJ0727, XJ0735, XJ0737 & piggery & 2007.Jul & Culex spp. \\
\hline & XJ0740, XJ0746, XJ0753 & piggery & 2007.Jul & $\begin{array}{l}\text { Aedes } \\
\text { dorsalis }\end{array}$ \\
\hline \multirow[t]{2}{*}{$\begin{array}{l}\text { Alertai, northern } \\
\text { Xinjiang }\end{array}$} & XJ0815, XJ0822, & piggery & 2008.Jul & $\begin{array}{l}\text { Aedes } \\
\text { dorsalis }\end{array}$ \\
\hline & XJ0837 & $\begin{array}{c}\text { cow } \\
\text { house }\end{array}$ & 2008.Jul & $\begin{array}{l}\text { Aedes } \\
\text { dorsalis }\end{array}$ \\
\hline \multirow[t]{2}{*}{ Shanxi } & SX0771 & piggery & 2007.Aug & $\begin{array}{l}\text { Culex } \\
\text { pipiens } \\
\text { pallens }\end{array}$ \\
\hline & SX0794 & piggery & 2007.Aug & $\begin{array}{l}\text { Aedes } \\
\text { dorsalis }\end{array}$ \\
\hline Qinghai & QH07130 & $\begin{array}{l}\text { reed } \\
\text { field }\end{array}$ & 2007.Aug & $\begin{array}{l}\text { Culex } \\
\text { modestus }\end{array}$ \\
\hline Liaoning & NE9712, NE9731 & piggery & 1997 & $\begin{array}{l}\text { Aedes } \\
\text { dorsalis }\end{array}$ \\
\hline Indonesia & JKT6423 & & 1980 & \\
\hline
\end{tabular}


encephalitis occurs in the areas where LNV is found in China $[14,15]$, future research should investigate the potential association of LNV and human diseases.

\section{Acknowledgements}

This work was supported by grants from the Ministry of Science and Technology of China (no. 2008ZX10004-001), China CDC-US CDC Cooperative Agreement U19-GH000004, The Young Scholar Scientific Research Foundation of China CDC (no.2010A105) and Development Grant of State Key Laboratory for Infectious Disease Prevention and Control (2008SKLID105). The authors thank Dr. Roger S. Nasci of the U.S. Centers for Disease Control and Prevention for consultation and assistance in the preparation and writing of this manuscript.

\section{Author details}

'State Key Laboratory for Infectious Disease prevention and Control, Institute for Viral Disease Control and Prevention, Chinese Center for Disease Control and Prevention, Beijing, People's Republic of China. ${ }^{2}$ Xinjiang Center for Disease Control and Prevention, Xinjiang, People's Republic of China.

\section{Authors' contributions}

ZL, XJL, QD, SZ, SXT, MHL and WJL collected the mosquitoes sample. ZL, SHF, MHL and WJL did virus isolation, RT PCR and sequencing studies. ZL and $\mathrm{HL}$ did the Bioinformatics analysis. ZL, HL, QT and GDL conceived the study and drafted the manuscript. All authors read and approved the final manuscript.

\section{Competing interests}

The authors declare that they have no competing interests.

Received: 12 April 2011 Accepted: 8 June 2011 Published: 8 June 2011

\section{References}

1. Attoui H, Mohd Jaafar F, Belhouchet M, Tao S, Chen B, Liang G, Tesh RB, de Micco $P$, de Lamballerie $X$ : Liao ning virus, a new Chinese seadornavirus that replicates in transformed and embryonic mammalian cells. J Gen Virol 2006, 87:199-208.

2. Xu PT, Wang YM, Zuo JM, Lin JW, Xu PM: Isolation of orbiviruses from sera of patients with unknown fever and encephalitis collected from Yunnan Province. Chin J Virol 1990, 6:27-33, Article in Chinese.

3. Lu XJ, Lu Z, Sun XH, Fu SH, Wang HQ, Tong SX, Zhang S, Attoui H, Liang GD: 0507JS60 virus isolated in Xinjiang was identified as Liaoning virus. Bing Du Xue Bao 2008, 24:438-442, Article in Chinese.

4. Li WJ, Wang JL, Li MH, Fu SH, Wang HY, Wang ZY, Jiang SY, Wang XW, Guo P, Zhao SC, Shi Y, Lu NN, Nasci RS, Tang Q, Liang GD: Mosquitoes and mosquito-borne arboviruses in the Qinghai-Tibet Plateau-focused on the Qinghai area, China. Am J Trop Med Hyg 2010, 82:705-711.

5. Li MH, Meng WS, Fu SH, Cheng JX, Zhao JY, Kong XS, Dai PF, Liang GD: Arbovirus investigation in some regions of Shanxi province in 2007. Zhong Hua Shi Yan He Lin Chuang Bing Du Xue Za Zhi 2009, 23:32-34, Article in Chinese.

6. Drummond AJ, Ho SY, Phillips MJ, Rambaut A: Relaxed phylogenetics and dating with confidence. PLoS Biol 2006, 4:e88.

7. Talbi C, Holmes EC, de Benedictis P, Faye O, Nakouné E, Gamatié D, Diarra A, Elmamy BO, Sow A, Adjogoua EV, Sangare O, Dundon WG, Capua I, Sall AA, Bourhy $\mathrm{H}$ : Evolutionary history and dynamics of dog rabies virus in western and central Africa. J Gen Virol 2009, 90(Pt 4):783-791.

8. Vasilakis1 Nikos, Deardorff1 REleanor, Kenney1 LJoan, Rossi1 LShannan, Hanley AKathryn, Weaver1 CScott: Mosquitoes Put the Brake on Arbovirus Evolution: Experimental Evolution Reveals Slower Mutation Accumulation in Mosquito Than Vertebrate Cells. PLoS Pathog 2009, 5:e1000467.

9. Ramírez A, Fajardo A, Moros Z, Gerder M, Caraballo G, Camacho D, Comach G, Alarcón V, Zambrano J, Hernández R, Moratorio G, Cristina J, Liprandi F: Evolution of Dengue Virus Type 3 Genotype III in Venezuela: Diversification, Rates and Population Dynamics. Virol J 2010, 7:329.

10. Nomikou K, Dovas Cl, Maan S, Anthony SJ, Samuel AR, Papanastassopoulou M, Maan NS, Mangana O, Mertens PP: Evolution and Phylogenetic Analysis of Full-Length VP3 Genes of Eastern Mediterranean Bluetongue Virus Isolates. PLOS ONE 2009, 4:e6437.
11. Liu H, Li MH, Zhai YG, Meng WS, Sun XH, Cao YX, Fu SH, Wang HY, Xu LH, Tang Q, Liang GD: Banna virus, China, 1987-2007. Emerg Infect Dis 2010, 16:514-517.

12. Sun X, Fu S, Gong Z, Ge J, Meng W, Feng Y, Wang J, Zhai Y, Wang $H$, Nasci R, Wang H, Tang Q, Liang G: Distribution of arboviruses and mosquitoes in northwestern Yunnan Province, China. Vector Borne Zoonotic Dis 2009, 9:623-630.

13. Liu H, Gao X, Liang G: Newly recognized mosquito-associated viruses in mainland China, in the last two decades. Virol J 2011, 8:68.

14. Gao XY, Nasci RS, Liang GD: The neglected arboviral infections in mainland China. PLoS Negl Trop Dis 2010, 4:e624.

15. Liang GD: Arboviruses-a field that should be urgently strengthened in China. Chin J Exp Clin Virol 2005, 19:305-306.

doi:10.1186/1743-422X-8-282

Cite this article as: Lu et al:: Liao ning virus in China. Virology Journal 2011 8:282.

\section{Submit your next manuscript to BioMed Central and take full advantage of:}

- Convenient online submission

- Thorough peer review

- No space constraints or color figure charges

- Immediate publication on acceptance

- Inclusion in PubMed, CAS, Scopus and Google Scholar

- Research which is freely available for redistribution 